squamous(59.5\%). Surgical approach was: 49.5\% MIS(robotic or laparoscopic), 34.4\% $\mathrm{AH}$ and $14.7 \% \mathrm{CVLH}$. 70.9\% underwent radical hysterectomy and $76.5 \%$ had pelvic lymph node assessment. There were 5 recurrences (MIS:1, AH:4, CVLH:0). No significant difference in 5-year RFS $\mathbf{( 9 6 . 2 \%}$ MIS, 93.7\% AH, 89.4\% CVLH, $\mathrm{p}=0.36$ ) was found. When limiting to patients with IA1 LVSI+/IA2 $(n=194)$, survival results were similar. Further, there was no significant difference in peri-operative complications $(\mathrm{p}>0.15)$. Patients undergoing MIS had a shorter median length of stay(1 day vs 3 $(\mathrm{AH})$ vs. $1.5(\mathrm{CVLH}), \mathrm{p}<0.01)$, but had more readmissions $(13.8 \%$ vs $6.5 \%(\mathrm{AH}), 5.2 \%(\mathrm{CVLH}), \mathrm{p}=0.036)$ and $\mathrm{ER}$ visits (15.9\%, 3.6\%(AH), 3.5\%(CVLH),p<0.01).

Conclusions In patients with microinvasive cervical cancer, there was no difference in survival by surgical approach, possibly due to low event rate. These patients may benefit from MIS without compromising oncologic outcomes.

\section{EPV063/\#357 THE IMPACT OF SURGICAL APPROACH IN CASES WITH NO RESIDUAL DISEASE ON HYSTERECTOMY SPECIMEN: A 4C (CANADIAN CERVICAL CANCER COLLABORATIVE) WORKING GROUP STUDY}

${ }^{1} \mathrm{C}$ Aubrey* ${ }^{2} \mathrm{G}$ Pond, ${ }^{3} \mathrm{~L}$ Helpman, ${ }^{4} \mathrm{D}$ Vicus, ${ }^{5} \mathrm{~L}$ Elit, ${ }^{6} \mathrm{M}$ Plante, ${ }^{7} \mathrm{~S} L a u^{8}{ }^{8} \mathrm{~K}$ Kwon ${ }^{9} \mathrm{~A}$ Altman, ${ }^{10} \mathrm{~K}$ Willows, ${ }^{11} \mathrm{~T}$ Feigenberg, ${ }^{12} \mathrm{~J}$ Sabourin, ${ }^{13} \mathrm{~V}$ Samouelian, ${ }^{5} \mathrm{~N}$ Cockburn, ${ }^{14} \mathrm{~S}$ Piedimonte, ${ }^{6} \mathrm{~L}-\mathrm{A}$ Teo-Fortin, ${ }^{14} \mathrm{SR}$ Kim, ${ }^{10} \mathrm{~N}$ Sadeq, ${ }^{12} \mathrm{~S}$ Shamiya, ${ }^{1} \mathrm{G}$ Nelson. ${ }^{1}$ University of Calgary, Department of Oncology, Division of Gynecologic Oncology, Calgary, Canada; ${ }^{2}$ McMaster University, Juravinski Cancer Center, Hamilton Health Sciences, Oncology, Hamilton, Canada; ${ }^{3}$ Juravinski Cancer Center, Gynecologic Oncology, Hamilton, Canada; ${ }^{4}$ Sunnybrook Health Sciences Centre, Gynecologic Oncology, Toronto, Canada; ${ }^{5}$ McMaster University, Juravinski Cancer Center, Hamilton Health Sciences, Gynecologic Oncology, Hamilton, Canada; ${ }^{6}$ Hotel Dieu de Quebec, Gynecologic Oncology, Quebec, Canada; ${ }^{7}$ McGill University, Jewish General Hospital, Gynecologic Oncology, Montreal, Canada; ${ }^{8}$ Vancouver General Hospital, Gynecologic Oncology, Vancouver, Canada; ${ }^{9}$ University of Manitoba, Gynecologic Oncology, Winnipeg, Canada; ${ }^{10}$ Dalhousie University, Gynecologic Oncology, Halifax, Canada; ${ }^{11}$ Trillium Health Partners, Gynecologic Oncology, Mississauga, Canada; ${ }^{12}$ University of Alberta, Gynecologic Oncology, Edmonton, Canada; ${ }^{13}$ Centre Hospitalier de I'Université de Montréal, Gynecologic Oncology, Montreal, Canada; ${ }^{14}$ University of Toronto, Gynecologic Oncology, Toronto, Canada

\subsection{6/ijgc-2021-IGCS.131}

Objectives The adverse effect of laparoscopic/robotic surgery in cervical cancer has been established, however the exact patient population that this applies to has not been fully elucidated. Our objective was to characterize the impact of surgical approach on outcomes in cases of no residual cervical cancer on hysterectomy specimen.

Methods Retrospective cohort study of cases of surgically treated cervical cancer at 10 Canadian institutions from 20072019. Cases with no residual disease on hysterectomy specimen were included and subdivided according to: minimally invasive (MIS), abdominal (AH) or combined vaginal-laparoscopic hysterectomy (CVLH). Recurrence free survival (RFS) and overall survival (OS) were estimated using Kaplan-Meier analysis. Chi-square and log-rank tests were used to compare between cohorts.

Results Within the total cohort, $187 / 1070$ (17.5\%) had no residual disease on hysterectomy specimen. The distribution according to surgical approach was: $94 \mathrm{MIS}, 78 \mathrm{AH}$, and 15 CVLH. The majority of cases undergoing MIS and AH were stage IB (51\% and 60\%), and underwent a radical hysterectomy $(91 \%$ and $67 \%)$, whereas of CVLH patients, the majority were stage IA (93\%) and underwent a simple hysterectomy (73\%). There were no significant differences in RFS (5-year:
MIS 96.0\%, AH 90.7\%, CVLH $100 \%, p=0.15)$ or OS $(5-$ year: MIS 98.4\%, AH 93.0\%, CVLH 100\%, $p=0.067$ ), although event-rates were low, and regression analysis was not performed.

Conclusions In this study of impact of surgical approach in cases with no residual cervical cancer on hysterectomy specimen, significant differences in RFS and OS among the surgical subgroups was not found. Further studies are warranted.

\section{EPV064/\#359 RADICAL ROBOTIC HYSTERECTOMY - EXPERIENCE OF 103 CASES AT THE NATIONAL CANCER INSTITUTE, RIO DE JANEIRO, BRAZIL}

${ }^{1} \mathrm{G}$ Guitmann, 'B Silvestre ${ }^{*},{ }^{2}$ Small, ${ }^{2} \mathrm{AC}$ de Melo. 'Brazilian National Cancer Institute, Division of Oncogynecology, Rio de Janeiro, Brazil; ${ }^{2}$ Brazilian National Cancer Institute, Division of Clinical Research, Rio de Janeiro, Brazil

\subsection{6/ijgc-2021-IGCS.132}

Objectives To evaluate the morbidity, mortality, recurrence and survival of patients diagnosed with cervical cancer undergoing treatment by robotic surgery at the Brazilian National Cancer Institute

Methods Patients diagnosed with adenocarcinoma and squamous cell carcinoma staging IA 1 through Ib1 treated surgically via DA vinci Si were included. Hazard Hatios (HR) through Cox's semiparametric model and the analyzes carried out in the environment $\mathrm{R}$ ver 4.0.3; considered significant $\mathrm{p}<0.05$. Results 103 medical records of patients diagnosed with cervical cancer treated by robotic route in the period from 2012 to 2018 were analyzed; 03 patients were excluded due to histopathology being neuroendocrine and in-situ. The most commonly performed radical hysterectomy: Type C1 $(\mathrm{n}=46) .76$ patients with the histological type of squamous carcinoma. 64 patients had a tumor less than or equal to $2 \mathrm{~cm} .13$ patients had recurrence of the disease. 9 patients died. Patients with tumors smaller than $2 \mathrm{~cm}$ had a 96\% disease-free survival. In the multivariate analysis, tumor size greater than $2 \mathrm{~cm}$ was a factor of worse prognosis with HR 16.79 (3.35-84.26, p = 0.001).

Conclusions In the retrospective analysis of patients diagnosed with adenocarcinoma or squamous cell carcinoma of the uterine cervix undergoing robotic surgical treatment, it was observed through multivariate analysis that the tumor size $>2$ $\mathrm{cm}$ behaved with an isolated factor with a worse prognosis.

\section{EPV065/\#372 ROLE FOR NEOADJUVANT CHEMOTHERAPY AND LESS INVASIVE SURGERY IN MANAGEMENT OF EARLY STAGE CERVICAL CANCER IN BOTSWANA}

${ }^{1} S$ Tuli* ${ }^{1}{ }^{1} \mathrm{~J}$ George, ${ }^{2} \mathrm{R}$ Luckett, ${ }^{3} \mathrm{P}$ Gaolebale, ${ }^{4} \mathrm{~B}$ Monare, ${ }^{5} \mathrm{~L}$ Bazzett-Matabele, ${ }^{6} \mathrm{~K}$ Schmeler, ${ }^{7} \mathrm{~S}$ Grover. ' University of California, Irvine, Donald Bren School of Information and Computer Sciences, Irvine, USA; '2Princess Marina Hospital, Bidmc, Gaborone, Botswana; ${ }^{3}$ Ancora Women's Clinic, Obstetrics and Gynaecology, Gaborone, Botswana; ${ }^{4}$ Princess Marina Hospital, Cenvical Cancer Screening Program, Gaborone, Botswana; ${ }^{5}$ Ochsner Medical Center, Obstetrics and Gynecology, New Orleans, USA; ${ }^{6}$ University of Texas MD anderson Cancer Center, Gynecologic Oncology and Reproductive Medicine, Houston, USA; ' University of Pennsylvania, Department of Radiation Oncology, Philadelphia, USA

10.1136/ijgc-2021-IGCS.133

Objectives Most patients with early stage cervical cancer are treated with a radical hysterectomy and lymph node dissection 
(LND). However, several low- and middle-income countries lack gynecological oncology expertise. We present our outcomes from treating patients with stage IA2-IB1 cervical cancer with neoadjuvant chemotherapy (NACT) followed by a simple hysterectomy and LND in absence of a gynecological oncologist.

Methods Between 2017 and 2019, 8 women with early stage cervical cancer (IA2-IB1) with tumor size less than $2 \mathrm{~cm}$ and absence of lymphovascular invasion in Botswana were treated with 3 cycles of NACT (carboplatin and paclitaxel) followed by a simple hysterectomy and pelvic LND performed by a general gynecologist.

Results The median age at surgery was 50 years (42-63). Six women $(75 \%)$ had stage IB1 disease. Six women (75\%) were HIV-positive. Three patients (38\%) had a pathological complete response with no detectable tumor on final pathology, and the other 5 patients $(62 \%)$ had a partial response to chemotherapy and were able to undergo surgery. All patients completed chemotherapy as prescribed. None of the women had any high risk features consistent with Peters or Sedlis criteria. Median follow-up time was 3.5 years. One patient died 6 months after treatment due to a non-cancer related cause (accident). Overall survival for all patients was $87.5 \%$ and cause-specific survival was $100 \%$.

Conclusions These pilot data suggest favorable outcomes with NACT followed by a simple hysterectomy and LND for women with early stage cervical cancer in Botswana.

\section{EPV066/\#382 PRELIMINARY RESULTS OF NIRAPARIB AND BRIVANIB DUAL THERAPY EVALUATION IN RECURRENT, METASTATIC AND PERSISTENT CERVICAL CANCER (CQG0G0101: AN OPEN- LABEL, SINGLE ARM, PHASE II CLINICAL TRIAL}

D Zou*, H Wang, J Shu, Q Zhou. Chongqing University Cancer Hospital, The Gynecologic Oncology Center, Chongqing, China

\subsection{6/ijgc-2021-IGCS.134}

Objectives The aim of this study (CQGOG 0101) is to evaluate the safety and activity of Niraparib (an oral PARP1/2 inhibitor) combined with brivanib in patients with recurrent, metastatic, or persistent cervical cancer.

Methods The CQGOG0101 study is an open-label, single-arm, single-center, phase 2 trial.

Results Between May 8th, 2020 and Jan 22nd, 2021, 9 patients (median age, 50 years old [28-73]) were enrolled. Patients had received a median of two (1-3) previous lines of platinum-based therapy. All of nine patients had distant metastatic lesions and had underwent at least one post-baseline tumor assessment (To deadline for submission), including 1 confirmed partial response, 4 with stable disease, 4 with progressive disease. Median duration of treatment was 3.8 months (3-8.2), three patients were still on treatment. No drug-related

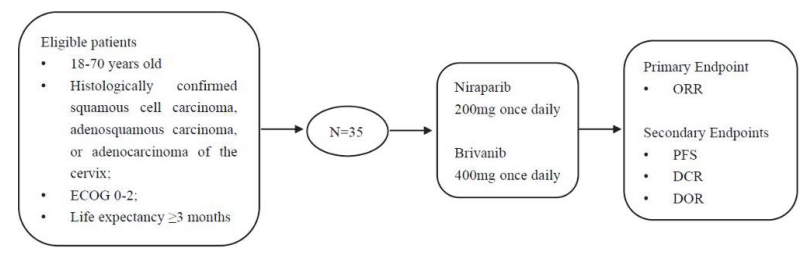

Abstract EPV066/\#382 Figure 1 Study design
Abstract EPV066/\#382 Table 1 Brief inclusion and exclusion criteria

\begin{tabular}{|c|c|}
\hline Inclusion Criteria: & Exclusion Criteria: \\
\hline $\begin{array}{l}\text { 1. Subjects join the strdy voluntarily and } \\
\text { sign the informed consent; } \\
\text { 2. The damage caused by other treatments } \\
\text { has recovered (NCI CTCAE } 5.0 \text { version } \\
\text { grade } \leq 1 \text { ), ECOG physical status score } \\
\text { is } 0-2 \text {; } \\
\text { 3. Life expectancy } \geq 3 \text { months; } \\
\text { 4. Female subjects are } 18 \text { to } 70 \text { years old; } \\
\text { 5. Histologically confirned squamous cell } \\
\text { carcinoma, adenosquamous carcinoma, } \\
\text { or adenocarcinoma of the cervix; } \\
\text { 6. Subjects with recurrent, persistent or } \\
\text { metastatic cervical cancer not amenable } \\
\text { to curative treatment with surgery and/or } \\
\text { radiation therapy; } \\
\text { measurable lesions must be required: a } \\
\text { tumor lesion has a long diametcr } \geq 5 \text { mm } \\
\text { and a lymph node must be } 10 \text { mm in } \\
\text { short axis when assessed by CT scan, } \\
\text { CT scan slice thickness recommended to } \\
\text { be no greater than } 5 \text { mm (defined by } \\
\text { RECIST } 1.1 \text { ) } \\
\text { 8. Subjects agree to take a blood sample; } \\
\text { 9. Subjects have enough organ function; } \\
\text { 10. Women of child-bearing age should } \\
\text { have negative results of serum or urine } \\
\text { pregnancy test within } 14 \text { days before } \\
\text { recruited and must not be in lactation. } \\
\text { Women are willing to adopt the } \\
\text { appropriate methods of contraception } \\
\text { during the trial and } 3 \text { months after last } \\
\text { administration. }\end{array}$ & $\begin{array}{l}\text { 1. Patients who are known to be allergic to } \\
\text { niraparib or the active or inactive } \\
\text { ingredients of drugs with similar } \\
\text { chemical structure to niraparib } \\
\text { 2. Patients who are known to be allergic to } \\
\text { toripalimab or the active or inactive } \\
\text { ingredients of drugs with similar } \\
\text { chemical structure to toripalimab } \\
\text { 3. Factors that signuficantly affect the } \\
\text { absorption of oral drugs, such as } \\
\text { inability to swallow, chronic diarhea, } \\
\text { and intestinal obstruction with clinical } \\
\text { significance; } \\
\text { 4. Patients with symptomatic, } \\
\text { uncontrol-lable brain metastases or pial } \\
\text { metastases. } \\
\text { 5. Major surgery was performed within } 3 \\
\text { weeks before enrollment; } \\
\text { 6. Palliative radiotherapy was performed } \\
\text { on >20\% bone marrow within } 1 \text { week } \\
\text { before onrollment; } \\
\text { 7. Aggressive cancer other than cervical } \\
\text { cancer has been diagnosed within } 2 \\
\text { years before cnrollment (except for } \\
\text { fully treated basal or squamous cell } \\
\text { skin cancer); } \\
\text { 8. Patients who have previously or } \\
\text { currently diagnosed myelodysplastic } \\
\text { syndrome (MDS) or acute myeloid } \\
\text { lenkemia (AML); } \\
\text { 9. Serions or uncontrolled diseases, } \\
\text { including but not limited to: } \\
\text { i. Uncontrollable nausea and } \\
\text { vomiting, inability to swallow the } \\
\text { study drug, any gastrointestinal } \\
\text { disease that may interfere with the } \\
\text { absorption and metabolism of the } \\
\text { drug, Uncontrolled grand mal seizures, } \\
\text { unstable spinal cord compression, }\end{array}$ \\
\hline
\end{tabular}

grade 3 or worse treatment-emergent adverse events were detected, the most common grade 1-2 adverse events (AEs) included: neutropenia (4 of 9 patients), anemia (2 of 9 patients), thrombocytopenia (1 of 9 patients), hypertension (2 of 9 patients), proteinuria(1 of 9 patients), fatigue (1 of 9 patients), and increased ALT/AST (1 of 9 patients).

Conclusions This combo seems to show a similar efficacy compared to other recurrent cervical cancer late-line therapies. We are also seeking to amend the protocol and explore niraparib combined with immunotherapy in recurrent CC in our trial later. Clinical trial information: NCT04395612.

\section{EPV067/\#391 QUALITY CONTROL IN EARLY STAGE CERVICAL CANCER MANAGEMENT: A SINGLE-INSTITUTION'S EXPERIENCE}

JE Shim*, MK Kim, YH Kim, SC Kim. Ewha Womans University Mokdong Hospital, Gynaecology and Obstetrics, Seoul, Korea, Republic of

\subsection{6/ijgc-2021-IGCS. 135}

Objectives Institutional quality control measures, such as monthly quality assessment meetings and stricter patient selection criteria for operation method, have been implemented since 2014 to better monitor cancer patient management. In this study, we evaluated effects of such monitoring on the clinical outcomes of cervical cancer patients. 